\title{
Clinical efficacy of aspirin combined with clopidogrel in treating cerebral infarction and its effect on serum hs-CRP, sICAM-1 and TNF- $\alpha$
}

\author{
MIN LI ${ }^{1 *}$, JING WANG $^{2 *}$, XINHONG WANG ${ }^{3}$ and GUOJIE $\mathrm{LI}^{4}$ \\ Departments of ${ }^{1}$ Neurology, ${ }^{2}$ Oncology and ${ }^{3}$ Nephrology, Yidu Central Hospital of Weifang, \\ Weifang, Shandong 262500; ${ }^{4}$ Department of Internal Neurology, Anqiu People's Hospital, \\ Anqiu, Shandong 262100, P.R. China
}

Received September 26, 2019; Accepted November 22, 2019

DOI: $10.3892 /$ etm.2019.8275

\begin{abstract}
Clinical efficacy of aspirin combined with clopidogrel in treating cerebral infarction and its influence on serum high-sensitivity C-reactive protein (hs-CRP), soluble intercellular adhesion molecule-1 (sICAM-1) and tumor necrosis factor- $\alpha$ (TNF- $\alpha$ ) were explored. Ninety patients with acute cerebral infarction treated in Yidu Central Hospital of Weifang were analyzed, and those treated with aspirin alone were group $\mathrm{A}(\mathrm{n}=40)$ and those treated with aspirin and clopidogrel were group $B(n=50)$ according to the different treatment plans. The NIHSS score, total effective rate and incidence rate of adverse reactions after treatment and admission were compared between the two groups. The expression level of hs-CRP was detected by enzymelinked immunosorbent assay, and the expression levels of sICAM-1 and TNF- $\alpha$ were analyzed by radioimmunoassay before treatment and three weeks after surgery, respectively, and they were analyzed and compared. After treatment, the total effective rate of patients in group B was significantly higher than that of group A $(\mathrm{P}<0.05)$. The general clinical baseline information, NIHSS score, and the expression levels of hs-CRP, sICAM-1, and TNF- $\alpha$ of patients in group B were significantly improved after treatment compared with those before treatment $(\mathrm{P}<0.05)$, and the NIHSS score and the expression levels of serum hs-CRP, sICAM-1, and TNF- $\alpha$ of those in group B were significantly lower than those in group $\mathrm{A}(\mathrm{P}<0.05)$. Combination therapy of aspirin and
\end{abstract}

Correspondence to: $\mathrm{Dr}$ Guojie Li, Department of Internal Neurology, Anqiu People's Hospital, 246 Jiankang Road, Anqiu, Shandong 262100, P.R. China

E-mail: g8u3jr@163.com

*Contributed equally

Key words: clopidogrel, combined medication, high-sensitivity C-reactive protein, soluble intercellular adhesion molecule-1, tumor necrosis factor- $\alpha$, cerebral infarction, aspirin clopidogrel can improve cerebral infarction effectively, and inhibit the expression levels of hs-CRP, sICAM-1 and TNF- $\alpha$ more effectively than aspirin alone.

\section{Introduction}

Cerebral infarction is a common brain disease. Due to its danger and the rapid increase in the number of patients (1), this disease has become one of the diseases with high mortality in the world. Clinically, cerebral infarction is caused by cerebral tissue necrosis and low oxidation due to insufficient blood supply caused by cerebral vascular stenosis and thrombosis of patients. With the further deterioration of the condition of patients, cognitive impairment caused by cerebral infarction will gradually worsen, eventually leading to dementia, affecting their quality of daily life (2-4). Therefore, the choice of treatment plan for cerebral infarction is an important medical research direction.

According to long-term clinical trials, acute cytokines such as high-sensitivity C-reactive protein (hs-CRP), serum soluble intercellular adhesion molecule-1 (sICAM-1) and tumor necrosis factor- $\alpha(\mathrm{TNF}-\alpha)$ are closely related to cerebral infarction, especially acute cerebral infarction $(5,6)$. Hs-CRP, as an acute inflammatory response protein, has the function of destroying vascular endothelium, and can activate platelet activity, promote platelet aggregation and increase the probability of thrombosis (7), thus increasing the probability of cerebral thrombosis. The mechanism of action of TNF- $\alpha$ in cerebral infarction is that free radicals produced by TNF- $\alpha$ may damage vascular endothelial cells, cause vasoconstriction, aggravate coagulation state, promote thrombosis, and eventually lead to ischemia, hypoxia and even necrosis (8). SICAM-1 is an intercellular adhesion molecule, which can mediate leukocyte adhesion and aggregation, and can be used as a corresponding indicator in various diseases caused by atherosclerosis $(9,10)$. Therefore, hs-CRP, sICAM-1 and TNF- $\alpha$ can generally be used as detection factors for cardiovascular and cerebrovascular diseases including cerebral infarction.

Aspirin and clopidogrel are two common drugs that are often used clinically. Aspirin can reduce the incidence rate of 
thrombosis by inhibiting cyclooxygenase and inhibiting platelet release and aggregation in vivo. Clopidogrel, as an antiplatelet drug, can reduce the expression of CD40L, an inflammatory mediator, in activated platelets induced by adenosine diphosphate, and may have anti-inflammatory effect $(11,12)$. Because of their thrombotic and anti-inflammatory effects, they are often used in the treatment of cardiovascular and cerebrovascular diseases including cerebral infarction. This investigation was designed to explore the clinical efficacy of the combination of the two drugs in the treatment of cerebral infarction and their effects on serum-related cytokines hs-CRP, sICAM-1 and TNF- $\alpha$.

\section{Patients and methods}

General information. Ninety patients with acute cerebral infarction treated in Yidu Central Hospital of Weifang (Weifang, China) were analyzed. According to the different treatment plans of these patients, those treated with the combination of the two drugs were divided into group $B(n=50)$, and those treated with aspirin alone were group A $(n=40)$. Comparing the general clinical baseline data between group $\mathrm{B}$ and $\mathrm{A}$, the difference was not significant $(\mathrm{P}>0.05)$ (Table I).

Inclusion criteria: All patients included in this study were diagnosed and treated in the above hospital, and were confirmed as cerebral infarction with complete clinical data.

Exclusion criteria: i) Patients suffering from serious endocrine diseases; ii) patients whose onset time and admission time exceed $6 \mathrm{~h}$; iii) patients with gastrointestinal hemorrhage and gastrointestinal inflammation; iv) patients suffering from chronic liver diseases, adrenal gland diseases and serious heart diseases for a long time and (v) patients with long-term taboo symptoms related to surgical treatment of this disease.

The family members of the patients were informed by telephone, and an informed consent was signed voluntarily. The study was examined and approved by the Ethics Committee of Yidu Central Hospital of Weifang.

Methods. Group A: Patients were administered aspirin entericcoated tablets (SFDA approval no: H20065051; Shenyang Shuangding Pharmaceutical Co., Ltd.) $100 \mathrm{mg} /$ time, once a day for 3 weeks.

Group B: Patients were administered aspirin enteric-coated tablets combined with clopidogrel. Aspirin $100 \mathrm{mg} /$ time was taken orally first, followed by clopidogrel sulfate tablets (SFDA approval no: H20000542; Shenzhen Salubris Pharmaceutical Co., Ltd.) $75 \mathrm{mg} / \mathrm{time}$, once a day for 3 weeks.

Detection methods. A total of $4 \mathrm{ml}$ venous blood was taken at two time points, before the first treatment and three weeks after treatment, in the fasting state of the patient. Serum was obtained by low speed centrifugation for 4-5 min at $1,800 \mathrm{x} g$ at $4^{\circ} \mathrm{C}$. Enzyme-linked immunosorbent assay was used to detect the expression level of hs-CRP (SFDA Approval no: 2400848; Getein Biotechnology Co., Ltd.) BIOBASE2000 automatic enzyme immunoassay analyzer (Jinan Xinbeixi Biotechnology Co., Ltd.) was used; radioimmunoassay was used to analyze the expression levels of sICAM-1 (item no: im-E10088; Shanghai Kanglang Biotechnology Co., Ltd.) and TNF- $\alpha$ (item no: JLC7047-96T; Wuhan MSK Biotechnology Co., Ltd.); DFM-96
Table I. General clinical baseline data of group A and B n (\%) (mean $\pm \mathrm{SD})$.

\begin{tabular}{|c|c|c|c|c|}
\hline Variables & $\begin{array}{c}\text { Group A } \\
(n=40)\end{array}$ & $\begin{array}{c}\text { Group B } \\
(n=50)\end{array}$ & $\begin{array}{c}\text { t-test/ } \\
\chi^{2}\end{array}$ & P-value \\
\hline Sex & & & 0.639 & 0.424 \\
\hline Male & $31(77.5)$ & $35(70.00)$ & & \\
\hline Female & $9(22.5)$ & $15(30.00)$ & & \\
\hline Age (years) & & & 0.058 & 0.810 \\
\hline Below 60 & $8(20.00)$ & $9(18.00)$ & & \\
\hline 60 and above & $32(80.00)$ & $41(82.00)$ & & \\
\hline Weight (kg) & $65.54 \pm 11.03$ & $63.95 \pm 10.57$ & 0.696 & 0.487 \\
\hline Smoking & & & 0.002 & 0.962 \\
\hline Yes & $21(52.50)$ & $26(52.00)$ & & \\
\hline No & $19(47.50)$ & $24(48.00)$ & & \\
\hline Drinking & & & 0.143 & 0.706 \\
\hline Yes & $20(50.00)$ & $27(54.00)$ & & \\
\hline No & $20(50.00)$ & $23(46.00)$ & & \\
\hline Hyperlipidemia & & & 0.009 & 0.924 \\
\hline Yes & $18(45.00)$ & $22(44.00)$ & & \\
\hline No & $22(55.00)$ & $28(56.00)$ & & \\
\hline Hypertension & & & 2.431 & 0.119 \\
\hline Yes & $25(62.50)$ & $23(46.00)$ & & \\
\hline No & $15(37.50)$ & $27(54.00)$ & & \\
\hline Diabetes & & & 0.035 & 0.850 \\
\hline Yes & $20(50.00)$ & $26(52.00)$ & & \\
\hline No & $20(50.00)$ & $24(48.00)$ & & \\
\hline
\end{tabular}

SD, standard deviation.

radioimmunoassay $\gamma$ counter (Hefei Zhongchen Light Industrial Machinery Co., Ltd.) was used.

Observation indicators and evaluation standard. The NIHSS scores of patients in group A and B before and after treatment were compared (NIH Stroke Scale, NIHSS) (13). The levels of hs-CRP, TNF- $\alpha$ and sICAM-1 in blood samples taken from patients before and after treatment were compared between the two groups. The adverse reactions after treatment, such as gastrointestinal hemorrhage, malignant vomiting, allergy and arrhythmia, were compared between the two groups.

The total effective rates of patients in group A and B were compared: Evaluation criteria (14): i) Basic rehabilitation: dysfunction score reduced by $91-100 \%$ and degree of disability was 0 ; ii) markedly effective: dysfunction score reduced by 46-90\%, while the degree of disability was between 1 and 3; iii) effective: dysfunction score reduced by $18-45 \%$; iv) no change: dysfunction score decreased or increased $<18 \%$; v) deterioration: dysfunction score increased $>18 \%$; vi) death. Total effective rate $=$ basic rehabilitation + markedly effective + effective.

Statistical analysis. SPSS 19.0 (SPSS, Inc., Chicago, IL, USA) was used for statistical analysis of comprehensive data, $\chi^{2}$ test 


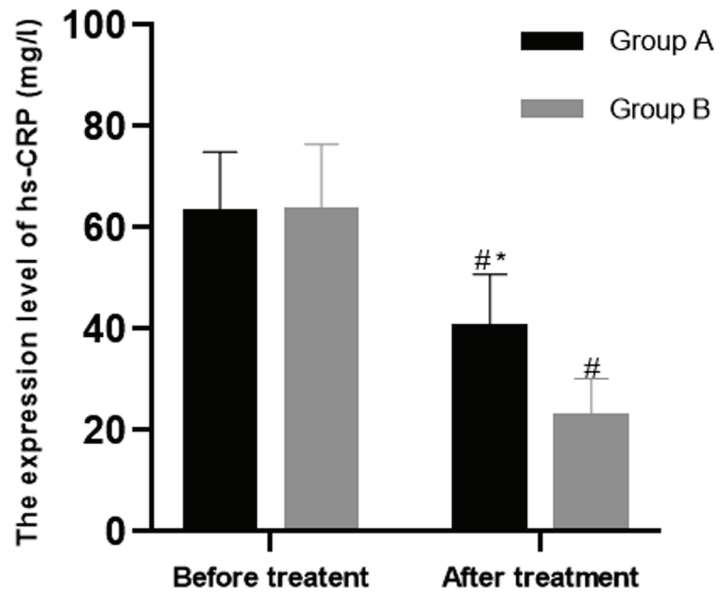

Figure 1. Comparison of the serum hs-CRP expression level of the two groups before and after treatment. Enzyme-linked immunosorbent assay was used to detect the hs-CRP expression level. Expression level of hs-CRP in the two groups after treatment was significantly lower than that before treatment, with statistical significance $(\mathrm{P}<0.0001)$. The expression level of hs-CRP in group B after treatment was significantly lower than that in group A, with statistical significance $(\mathrm{P}<0.0001)$. "Compared with group $\mathrm{A}(\mathrm{P}<0.05) ;{ }^{*} \mathrm{com}-$ pared with that after treatment $(\mathrm{P}<0.05)$. hs-CRP, high-sensitivity $\mathrm{C}$-reactive protein.

was used for counting data, and (mean \pm SD) for measurement data. Paired t-test was used for comparison of expression level before and after treatment in the same group. The expression levels of groups A and B at the same time point were compared by independent-samples t-test. P-value $<0.05$ was considered to be statistically significant.

\section{Results}

Comparison of general clinical baseline data of the two groups. Basic conditions of group A and B, such as age, sex, hypertension, hyperlipidemia, diabetes, and personal habits (smoking and drinking), were compared, and had significant differences $(\mathrm{P}>0.05)$ (Table I).

Comparison of the expression levels of serum-related cytokines before and after treatment between groups $A$ and $B$. i) Before treatment, the hs-CRP level of patients in group A was $62.89 \pm 12.05 \mathrm{mg} / \mathrm{l}$, while that of patients in group B was $63.27 \pm 13.20 \mathrm{mg} / 1$. There was no significant difference in hs-CRP level between the two groups before treatment ( $\mathrm{P}>0.05)$. The post-treatment levels of the two groups were $40.39 \pm 10.37 \mathrm{mg} / 1$ and $22.59 \pm 7.65 \mathrm{mg} / 1$, respectively, with significant difference $(\mathrm{P}<0.001)$. Comparing the levels of groups $\mathrm{A}$ and $\mathrm{B}$ after treatment, it was concluded that those of group B were significantly lower than those of group A after treatment $(\mathrm{P}<0.001)$ (Fig. 1).

ii) Before treatment, the TNF- $\alpha$ level of patients in group $A$ was $18.14 \pm 3.13 \mu \mathrm{g} / \mathrm{l}$, while that of patients in group B was $18.01 \pm 3.09 \mu \mathrm{g} / \mathrm{l}$. There was no significant difference in hs-CRP level between the two groups before treatment $(\mathrm{P}>0.05)$. The post-treatment levels of the two groups were $11.19 \pm 2.01 \mu \mathrm{g} / \mathrm{l}$ and $6.13 \pm 1.79 \mu \mathrm{g} / \mathrm{l}$ respectively $(\mathrm{P}<0.001)$. Comparing the levels of groups A and B after treatment, it was concluded that group $\mathrm{B}$ was significantly lower than group A $(\mathrm{P}<0.001)$ (Fig. 2).

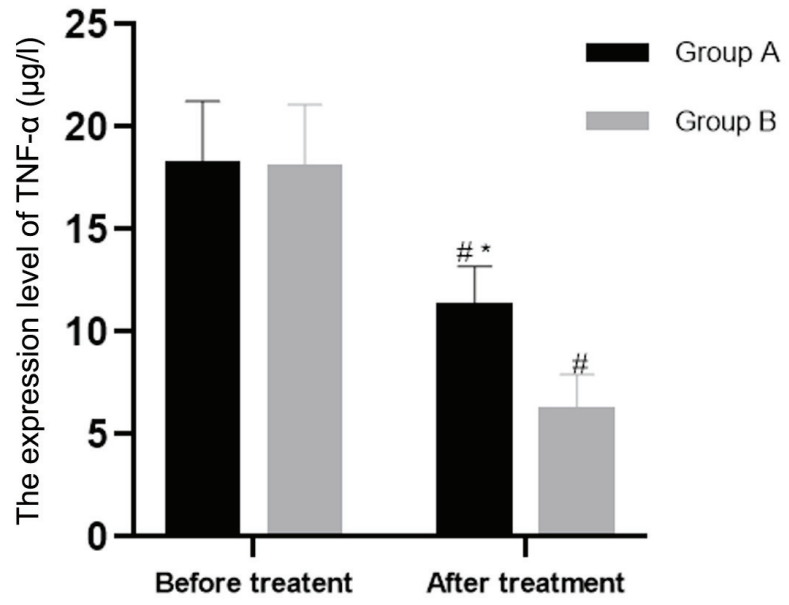

Figure 2. Comparison of the serum TNF- $\alpha$ expression level of the two groups before and after treatment. Radioimmunoassay was used to analyze TNF- $\alpha$ expression level. TNF- $\alpha$ expression level after treatment was significantly lower than that before treatment, with statistical significance $(\mathrm{P}<0.0001)$. The expression level of TNF- $\alpha$ in group B after treatment was significantly lower than that in group $\mathrm{A}$, with statistical significance $(\mathrm{P}<0.0001) .{ }^{*}$ Compared with group $\mathrm{A}(\mathrm{P}<0.05)$; ${ }^{*}$ compared with that after treatment $(\mathrm{P}<0.05)$. TNF- $\alpha$, tumor necrosis factor- $\alpha$.

iii) Before treatment, the level of serum-related cytokine sICAM-1 in group A was $444.74 \pm 20.78 \mathrm{ng} / \mathrm{ml}$, while that in group B was $448.31 \pm 22.01 \mathrm{ng} / \mathrm{ml}$. There was no significant difference in hs-CRP levels between the two groups before treatment $(\mathrm{P}>0.05)$. The post-treatment levels of the two groups were $272.77 \pm 12.48 \mathrm{ng} / \mathrm{ml}$ and $230.59 \pm 20.03 \mathrm{ng} / \mathrm{ml}$ respectively, with significant difference $(\mathrm{P}<0.001)$. Comparing the levels of groups A and B after treatment, it was concluded that those of group B were significantly lower than those of group A $(\mathrm{P}<0.001)$ (Fig. 3).

Comparison of NIHSS scores of patients in the two groups. Before treatment, the NIHSS score of patients in group A was $16.54 \pm 2.33$, while that in group B was $16.72 \pm 2.29$. There was no significant difference between the two groups before treatment $(\mathrm{P}>0.05)$. The post-treatment scores of the two groups were $7.18 \pm 0.72$ and $3.43 \pm 0.67$, respectively, with significant difference $(\mathrm{P}<0.001)$. NIHSS after treatment in group $\mathrm{B}$ was significantly lower than that in group $\mathrm{A}(\mathrm{P}<0.001)$ (Fig. 4).

Comparison of the clinical efficacy of patients in the two groups. Clinical efficacy of patients in the two groups were compared. In group A, there were 6 cases of basic rehabilitation, 15 cases of markedly effective, 10 cases of effective, 9 cases without change, and no deterioration or death; its total effective rate was $77.5 \%$. In group $\mathrm{B}$, there were 9 cases of basic rehabilitation, 20 cases of markedly effective, 19 cases effective, 2 cases without change, and no deterioration or death; its total effective rate was $96 \%$. The total effective rate of group B was significantly higher than that of group A, and the difference was significant $(\mathrm{P}<0.05)$ (Table II).

Comparison of adverse reactions of patients between the two groups. We observed the adverse reactions of gastrointestinal hemorrhage, malignant vomiting, allergy and arrhythmia. In group A, there were 3 cases of gastrointestinal hemorrhage, 
Table II. Comparison of total effective rate of clinical efficacy of patients between the two groups $[\mathrm{n}(\%)]$.

\begin{tabular}{lcccc}
\hline Variables & $\begin{array}{c}\text { Group A } \\
(\mathrm{n}=40)\end{array}$ & $\begin{array}{c}\text { Group B } \\
(\mathrm{n}=50)\end{array}$ & $\chi^{2}$ & P-value \\
\hline Basic rehabilitation & $6(15.00)$ & $9(18.00)$ & - & - \\
Markedly effective & $15(37.50)$ & $20(40.00)$ & - & - \\
Effective & $10(25.00)$ & $19(38.00)$ & - & - \\
No change & $9(22.50)$ & $2(4.00)$ & - & - \\
Deterioration & $0(0.00)$ & $0(0.00)$ & - & - \\
Death & $0(0.00)$ & $0(0.00)$ & - & - \\
Total effective & 77.50 & 96.00 & 7.089 & 0.0078 \\
rate $(\%)$ & & & & \\
\hline
\end{tabular}

$\chi^{2}$, Chi-square test.

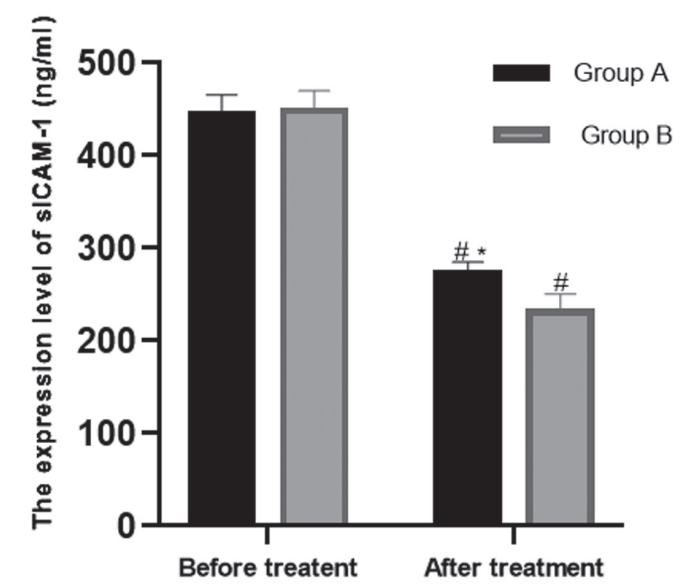

Figure 3. Comparison of the serum sICAM-1 expression level of the two groups before and after treatment. Radioimmunoassay was used to analyze the sICAM-1 expression level. Expression level of sICAM-1 after treatment was significantly lower than that before treatment, with statistical significance $(\mathrm{P}<0.0001)$; expression level of sICAM-1 in group B after treatment was significantly lower than that in group A, with statistical significance $(\mathrm{P}<0.0001)$. "Compared with group A $(\mathrm{P}<0.05)$; ${ }^{*}$ compared with that after treatment $(\mathrm{P}<0.05)$. sICAM-1, soluble intercellular adhesion molecule-1.

6 cases of malignant vomiting, 3 cases of allergy and 7 cases of arrhythmia, totaling 19 cases (47.5\%). In group B, there was 1 case of gastrointestinal hemorrhage, 1 case of malignant vomiting, 2 cases of allergy and 2 cases of arrhythmia, totaling 6 cases (12\%). The incidence of adverse reactions in group B was significantly lower than that in group A, and the difference was significant $(\mathrm{P}<0.05)$ (Table III).

\section{Discussion}

How to treat cerebral infarction more effectively is an important research issue. Thrombolysis (15) and antiplatelet therapy (16) are both effective methods to treat cerebral infarction. Its treatment with aspirin and clopidogrel is one of the commonly used methods. As a predictive diagnostic index for cerebral infarction (17), the expression level of relevant cytokines is upregulated in the brain after stroke, and the brain plug area is enlarged by infiltrating ischemic areas (18).
Table III. Comparison of adverse reactions of patients between the two groups $[\mathrm{n}(\%)]$.

\begin{tabular}{lcccc}
\hline Variables & $\begin{array}{c}\text { Group A } \\
(\mathrm{n}=40)\end{array}$ & $\begin{array}{c}\text { Group B } \\
(\mathrm{n}=50)\end{array}$ & $\chi^{2}$ & P-value \\
\hline $\begin{array}{l}\text { Gastrointestinal } \\
\text { hemorrhage }\end{array}$ & $3(7.50)$ & $1(2.00)$ & - & - \\
Malignant vomiting & $6(15.00)$ & $1(2.00)$ & - & - \\
Allergy & $3(7.50)$ & $2(4.00)$ & - & - \\
Arrhythmia & $7(17.50)$ & $2(4.00)$ & - & - \\
Total & $19(47.50)$ & $6(12.00)$ & 13.960 & 0.0002 \\
\hline
\end{tabular}

$\chi^{2}$, Chi-square test.

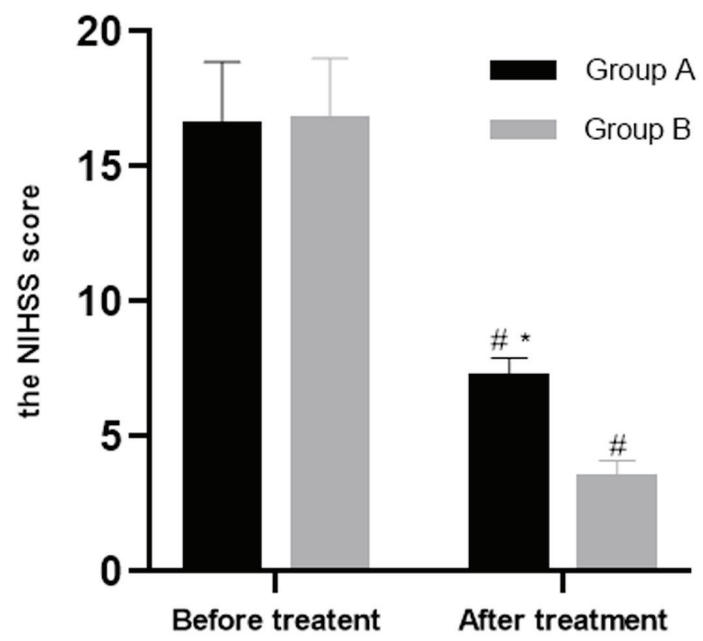

Figure 4. Comparison of the NIHSS scores of patients in the two groups. The NIHSS scores of patients in the two groups after treatment were significantly lower than those before treatment $(\mathrm{P}<0.0001)$, the NIHSS scores of group $\mathrm{B}$ after treatment were significantly lower than those of group A, and the differences were statistically significant $(\mathrm{P}<0.0001)$. ${ }^{*}$ Compared with group A $(\mathrm{P}<0.05)$; ${ }^{\#}$ compared with that after treatment $(\mathrm{P}<0.05)$.

The purpose of this study was to investigate the expression level and efficacy of common serum factors such as hs-CR, TNF- $\alpha$ (19), and sICAM-1 (20) under the influence of aspirin and clopidogrel in cerebral infarction.

In this study, we compared the differences in the expression levels of hs-CRP, sICAM-1 and TNF- $\alpha$ between groups A (aspirin only) and B (both drugs). After data analysis, we found that the expression levels of hs-CRP, sICAM-1 and TNF- $\alpha$ of patients in the two groups decreased compared with those before treatment. The decline in group B was significantly higher than that of group $\mathrm{A}$, and there were significant differences in statistics. Therefore, we believed that combined therapy could reduce the expression levels of hs-CRP, sICAM-1 and TNF- $\alpha$ more rapidy. In the study of $\mathrm{Yu}$ et al (21) clinical treatment of myocardial infarction, the levels of hs-CRP, TNF- $\alpha$ and other related cytokines after aspirin combined with clopidogrel were significantly lower than aspirin alone. In a study on the treatment of acute coronary syndrome with aspirin and clopidogrel, the expression level of hs-CRP and TNF- $\alpha$ decreased more obviously after aspirin 
and clopidogrel were treated together than aspirin alone (22). However, the study of Yin (23) on unstable angina pectoris, comparing the two experimental groups, a group with aspirin alone and a group with aspirin combined with clopidogrel, it was found that the level of serum factor sICAM-1 in the latter group decreased more significantly after one week of treatment compared with the former. These results were similar to the results in the present study, and proved that aspirin combined with clopidogrel was more effective in reducing the expression levels of hs-CRP, sICAM-1 and TNF- $\alpha$.

Our study also compared the total effective rate of clinical efficacy and adverse reactions of the two groups. It was discovered that the total effective rate of combined treatment of the two drugs was significantly higher than that of aspirin alone, with fewer adverse reactions. Therefore, we concluded that the efficacy and safety of aspirin combined with clopidogrel were better than aspirin alone. In the study of Wong et al (24) on stroke patients, clopidogrel combined with aspirin was more effective in reducing microembolization signals than aspirin alone. As to prevention of stroke or transient cerebral ischemia, Zhang et al (25) reported that compared with monotherapy, short-term aspirin combined with clopidogrel had a higher secondary prevention effect on prevention of stroke or transient cerebral ischemia without increasing the risk of hemorrhagic stroke and major hemorrhagic events, which was similar to our results.

In summary, the experimental results proved that the combined use of aspirin and clopidogrel had a stronger inhibitory effect on the expression levels of serum-related cytokines hs-CRP, TNF- $\alpha$ and sICAM-1 than aspirin alone, and reduced the expression levels of these factors, and achieved better results in clinical practice.

\section{Acknowledgements}

Not applicable.

\section{Funding}

No funding was received.

\section{Availability of data and materials}

The datasets used and/or analyzed during the present study are available from the corresponding author on reasonable request.

\section{Authors' contributions}

ML wrote the manuscript, interpreted and analyzed the data. JW and XW designed the study and performed the experiments. GL was responsible for the analysis and discussion of the data. All authors read and approved the final manuscript.

\section{Ethics approval and consent to participate}

The study was approved by the Ethics Committee of Yidu Central Hospital of Weifang (Weifang, China). Patients who participated in this research had complete clinical data. Signed informed consents were obtained from the patients and/or the guardians.

\section{Patient consent for publication}

Not applicable.

\section{Competing interests}

The authors declare that they have no competing interests.

\section{References}

1. Heit JJ, Ball RL, Telischak NA, Do HM, Dodd RL, Steinberg GK, Chang SD, Wintermark M and Marks MP: Patient outcomes and cerebral infarction after ruptured anterior communicating artery aneurysm treatment. AJNR Am J Neuroradiol 38: 2119-2125, 2017.

2. Guo A, Hao F, Li F, Wang B, Liu L, Zhao Z and Yao C: Basal ganglia cerebral infarction patient fMRI imaging analysis before and after acupuncture-medicine therapy. Biomed Res (Aligarh) 28: 9779-9783, 2017.

3. Tan XL, Xue YQ, Ma T, Wang X, Li JJ, Lan L, Malik KU, McDonald MP, Dopico AM and Liao FF: Partial eNOS deficiency causes spontaneous thrombotic cerebral infarction, amyloid angiopathy and cognitive impairment. Mol Neurodegener 10: 24, 2015.

4. Shankaran S, McDonald SA, Laptook AR, Hintz SR, Barnes PD, Das A, Pappas A and Higgins RD; Eunice Kennedy Shriver National Institute of Child Health and Human Development Neonatal Research Network: Neonatal magnetic resonance imaging pattern of brain injury as a biomarker of childhood outcomes following a trial of hypothermia for neonatal hypoxicischemic encephalopathy. J Pediatr 167: 987-993, 2015

5. Kitagawa K, Hosomi N, Nagai Y, Ohtsuki T, Kagimura T, Minematsu K, Uchiyama S and Matsumoto M: HS-CRP level is an independent predictor for recurrent stroke and vascular events in patients with non-cardiogenic brain infarction. J Neurol Sci 381: 869-870, 2017.

6. Pantović-Stefanović M, Petronijević N, Dunjić-Kostić B Velimirović M, Nikolić T, Jurišić V, Lačković M, Damjanović A, Totić-Poznanović S, Jovanović AA and Ivković M: sVCAM-1, sICAM-1, TNF- $\alpha$ and IL-6 levels in bipolar disorder type I: Acute, longitudinal and therapeutic implications. World J Biol Psychiatry 19: S41-S51, 2018.

7. Vila N, Castillo J, Dávalos A and Chamorro A: Proinflammatory cytokines and early neurological worsening in ischemic stroke. Stroke 31: 2325-2329, 2000.

8. Wang JH, Chen Q and Wang DL: Clinical efficacy of edaravone in combined with gangliosides in the treatment of acute cerebral infarction in elderly patients and the effect on inflammatory cytokines. Zhongguo Yiyuan Ganranxue Zazhi 25: 2179-2181, 2015 (In Chinese).

9. Liu ZJ, Yang QD, Liu YH, Huang XS and Zhang N: Changes and clinical significance of serum IL-6, sICAM-1 in patients with cerebral infarcts. Zhong Nan Da Xue Xue Bao Yi Xue Ban 29: 326-329, 2004 (In Chinese).

10. Ridker PM, Hennekens CH, Roitman-Johnson B, Stampfer MJ and Allen J: Plasma concentration of soluble intercellular adhesion molecule 1 and risks of future myocardial infarction in apparently healthy men. Lancet 351: 88-92, 1998.

11. Liu MC, Li FP, Han YL and Chen HS: Argatroban versus aspirin plus clopidogrel in the treatment of acute ischemic stroke: A pilot, randomised, open-label study. Med J Chin People's Liberation Army 40: 433-439, 2015.

12. CAPRIE Steering Committee: A randomised, blinded, trial of clopidogrel versus aspirin in patients at risk of ischaemic events (CAPRIE). Lancet 348: 1329-1339, 1996.

13. Naess H, Kurtz M, Thomassen L and Waje-Andreassen U: Serial NIHSS scores in patients with acute cerebral infarction. Acta Neurol Scand 133: 415-420, 2016.

14. Zhang X, Chen J, Ding M and Zhang N: Aspirin plus clopidogrel for angina pectoris in coronary heart disease patients. Int J Clin Exp Med 11: 13528-13534, 2018.

15. Wardlaw JM, Murray V, Berge E, del Zoppo G, Sandercock P, Lindley RL and Cohen G: Recombinant tissue plasminogen activator for acute ischaemic stroke: An updated systematic review and meta-analysis. Lancet 379: 2364-2372, 2012. 
16. Chen ZM, Sandercock P, Pan HC, Counsell C, Collins R, Liu LS, Xie JX, Warlow C and Peto R: Indications for early aspirin use in acute ischemic stroke: A combined analysis of 40,000 randomized patients from the Chinese acute stroke trial and the international stroke trial. On behalf of the CAST and IST collaborative groups. Stroke 31: 1240-1249, 2000.

17. Tuttolomondo A, Di Raimondo D, di Sciacca R, Pinto A and Licata G: Inflammatory cytokines in acute ischemic stroke. Curr Pharm Des 14: 3574-3589, 2008

18. Zhou Z, Zhang J, Li X, Xia C, Han Y and Chen H: Protein microarray analysis identifies key cytokines associated with malignant middle cerebral artery infarction. Brain Behav 7: e00746, 2017.

19. Zhang SQ, Fan H, Deng LJ and Wu D: Effects of Atorvastatin calcium combined with aspirin on serum levels of Hcy, NSE, UA, hs-CRP and inflammatory factors of patients with cerebral infarction. J Hainan Med Univ 23: 157-160, 2017.

20. Klein BR, Brown EN and Casden RS: Preoperative macular spectral-domain optical coherence tomography in patients considering advanced-technology intraocular lenses for cataract surgery. J Cataract Refract Surg 42: 537-541, 2016.

21. Yu HR, Wei YY, Ma JG and Geng XY: Beneficial effects of combined administration of clopidogrel and aspirin on the levels of proinflammatory cytokines, cardiac function, and prognosis in ST-segment elevation myocardial infarction: A comparative study. Medicine (Baltimore) 97: e13010, 2018.
22. Chen YG, Xu F, Zhang Y, Ji QS, Sun Y, Lü RJ and Li RJ: Effect of aspirin plus clopidogrel on inflammatory markers in patients with non-ST-segment elevation acute coronary syndrome. Chin Med J (Engl) 119: 32-36, 2006.

23. Yin G: The effect of cilostazol on serum level of sICAM-1, sVCAM-1 and MMP-9 in patients with unstable angina. Acta Academiae Medicinae Qingdao Universitatis 6: 532-534, 2007.

24. Wong KS, Chen C, Fu J, Chang HM, Suwanwela NC, Huang YN, Han Z, Tan KS, Ratanakorn D, Chollate P, et al; CLAIR study investigators: Clopidogrel plus aspirin versus aspirin alone for reducing embolisation in patients with acute symptomatic cerebral or carotid artery stenosis (CLAIR study): A randomised, open-label, blinded-endpoint trial. Lancet Neurol 9: 489-497, 2010.

25. Zhang Q, Wang C, Zheng M, Li Y, Li J, Zhang L, Shang X and Yan C: Aspirin plus clopidogrel as secondary prevention after stroke or transient ischemic attack: A systematic review and meta-analysis. Cerebrovasc Dis 39: 13-22, 2015.

This work is licensed under a Creative Commons Attribution-NonCommercial-NoDerivatives 4.0 International (CC BY-NC-ND 4.0) License. 